\title{
EFEKTIFITAS METODE SIMULASI : ROLE PLAY TERHADAP PENINGKATAN PENGETAHUAN MASYARAKAT TENTANG BASIC LIFE SUPPORT (BLS) DI KELURAHAN SETONO KABUPATEN PONOROGO
}

\author{
Filia Icha Sukamto1), Dianita Rifqia Putri2) \\ 1 Fakultas Ilmu Kesehatan Universitas Muhammadiyah Ponorogo \\ 2 Fakultas Ilmu Kesehatan Universitas Muhammadiyah Ponorogo \\ *correspondence author: Telepon: 081336054554, E-mail: filiaicha@gmail.com
}

DOI: https://doi.org/10.33859/dksm.v10i2.500

\begin{abstract}
Abstrak
Latar Belakang:Kualitas CPR sering diabaikan, faktor yang mempengaruhi adalah individu, pelatihan, kesadaran, teknik dan kelelahan penyelamat. Penolong pertama seringkali orang awam yang tidak memiliki kemampuan menolong yang memadai sehingga dapat dipahami jika penderita dapat meninggal ditempat kejadian atau selamat sampai ke fasilitas kesehatan dengan kecacatan.

Tujuan: Penelitian ini bertujuan mengetahui efektifitas metode simulasi: role play terhadap peningkatan pengetahuan masyarakat tentang Basic Life Support (BLS).

Metode: Jenis penelitian pre eksperimental, kuota sampling dengan sample 80 respoden. Instrumen berupa kuisioner, tehnik pengambilan data pre dan post test. Uji statistic bivariat dengan Mc Nemar. Hasil: Hasil penelitian menunjukkan tingkat pengetahuan pada pretest di dapatkan $53(66,2 \%)$ berpengetahuan buruk sedangkan tingkat pengetahuan posttest didapatkan $72(90 \%)$ berpengetahuan baik. Analisis data dengan uji statistic McNemar menunjukkan nilai significansi $=0,00$. Karena nilai $\mathrm{p}<0,05$ maka pengetahuan antara sebelum dan sesudah simulasi : role play berbeda secara bermakna. Simpulan: Adanya perbedaan yang bermakna antara pengetahuan sebelum dan sesudah simulasi : role play maka diharapkan pada pemberian informasi tidak hanya sekedar teori namun ada pratik berkesinambungan seperti pelatihan, untuk meningkatkan pengetahuan baik pada masyarakat awam guna membantu dalam pertolongan pertama.
\end{abstract}

Kata Kunci: Basic Life Support, Metode Simulasi : Role Play, Pengetahuan, Masyarakat 


\begin{abstract}
Background: Quality of CPR often overlooked. Factors that influence are individuals, training, awareness, techniques and savior fatigue. First helper often a lay person which doesn't have enough skills so it can be understood if the patient can die or survived with a disability.

Purpose: This study aims to determine the effectiveness of simulation role play method to increase public knowledge about Basic Life Support (BLS).

Method: Type research was Pre-experimental, quota sampling with 80 respondents. Data collection techniques use pre and post-test. Test bivariate statistics use McNemar.

Result: The results showed the level of knowledge at the pretest was $53(66.2 \%)$ with poor knowledge, while the post-test knowledge was 72 (90\%) with good knowledge. Data analysis with Mc Nemar test showed significance value $=0.00$ (value of $p<0.05$ ), the knowledge between before and after the role play simulation is significantly different.

Conclusion: The existence of a meaningful difference between knowledge before and after role play simulation, expected that the provision of information isn't just a theory but continuous practices like training, to increase good knowledge in ordinary people to help in first aid.
\end{abstract}

Keywords: Basic Life Support, Simulation Methods: Role Play, Knowledge, Society

\section{Pendahuluan}

Keadaan gawat darurat bisa terjadi

karena ulah manusia maupun alam, misalnya

bencana alam, banjir, gempa bumi, tsunami, gunung meletus, tanah longsor, ledakan bom, kegagalan tehnologi, kecelakaan lalulintas yang merupakan penyebab kematian utama baik di daerah pedesaan maupun perkotaan. Penolong pertama seringkali orang awam yang tidak memiliki kemampuan menolong yang memadai sehingga dapat dipahami jika penderita dapat langsung meninggal ditempat kejadian atau mungkin selamat sampai ke fasilitas kesehatan dengan mengalami kecacatan karena cara transport yang salah.
Pada penderita dengan kegagalan pernapasan dan jantung kurang dari 4-6 menit akan menyebabkan kerusakan otak yang ireversibel.

$$
\text { Henti napas disebabkan karena }
$$

stroke, tenggelam, keracunan dan henti jantung selain disebabkan karena penyakit jantung juga bisa karena jatuh atau kecelakaan. Kecelakaan lalulintas yang melibatkan kendaraan bermotor di Indonesia meningkat dari tahun 2012 hingga tahun 2014 yaitu dari 200.701 kasus menjadi 203.334 kasus atau mengalami kenaikan sebesar $4 \%$ (Departement Perhubungan, 2014). Jumlah 
Dinamika Kesehatan Jurnal Kebidanan dan Keperawatan Vol 10 No. 1 Juli 2019 ( ISSN: 2086-3454 EISSN: 2549-4058)

url: http://ojs.dinamikakesehatan.unism.ac.id DOI : https://doi.org/10.33859/dksm.v10i2

Efektifitas Metode Simulasi : Role Play Terhadap Peningkatan Pengetahuan Masyarakat Tentang Basic Life Support

(Bls) Di Kelurahan Setono Kabupaten Ponorogo

angka kematian menurut data dari Kepolisian

Republik Indonesia (2014) akibat kecelakaan

lalulintas adalah sejumlah 31.186 kasus. Data

tersebut juga menunjukkan bahwa secara rata

- rata korban meninggal sekitar 84 orang

setiap harinya atau 3-4 orang setiap jamnya.

Angka kejadian kecelakaan di ponorogo pada

tahun 2014 mencapai 412 kejadian dengan

korban meninggal dunia mencapai 98 orang.

Sedangkan angka kejadian kecelakaan

lalulintas mulai bulan Januari sampai Juni

2015 mencapai 313 korban dengan korban

meninggal dunia mencapai 40 orang (Data

LakaLantas, 2014-2015). Peneliti melakukan

wawancara kepada warga Kelurahan setono

ponorogo mengenai penanganan kecelakaan

lalulintas. Ketika terjadi kecelakaan lalulintas,

maka masyarakat menghubungi polisi

lalulintas dan polisi akan segera datang

kelokasi kejadian untuk mengamankan.

Warga juga menjelaskan bahwa warga tidak

tahu cara memberi pertolongan yang benar

sebelum korban dibawa ke rumah sakit .

Salah satu cara untuk memberikan

dan meningkatkan pengetahuan serta ketrampilan masyarakat adalah melalui

pelatihan atau pembelajaran dengan metode

yang sesuai, peralatan yang menunjang dan

instruktur yang kompeten dibidangnya. Salah

satu metode yang digunakan untuk

meningkatkan pengetahuan masyarakat

adalah dengan metode simulasi. Metode

simulasi merupakan salah satu metode

pembelajaran yang dapat digunakan dalam

pembelajaran kelompok. Proses pembelajaran

yang menggunakan metode simulasi

cenderung objeknya bukan benda atau

kegiatan yang sebenarnya, melainkan

kegiatan mengajar yang bersifat pura-pura

(Sri Anitah, W. DKK. 2012).

Basic Life Support (BLS) merupakan

penanganan pertama kegawat daruratan yang merupakan pelayanan pra Rumah Sakit dan respons cepat serta tepat untuk menyelamatkan nyawa dan mencegah kecacatan (time saving is life and limb saving) sebelum dirujuk kesarana rujukannya (rumah sakit) sesuai kebutuhan, maka dibentuk sarana PUBLIC SAFETY CENTRE (PSC) sebagai 
Dinamika Kesehatan Jurnal Kebidanan dan Keperawatan Vol 10 No. 1 Juli 2019 ( ISSN: 2086-3454 EISSN: 2549-4058)

url: http://ojs.dinamikakesehatan.unism.ac.id DOI : https://doi.org/10.33859/dksm.v10i2

Efektifitas Metode Simulasi : Role Play Terhadap Peningkatan Pengetahuan Masyarakat Tentang Basic Life Support

(Bls) Di Kelurahan Setono Kabupaten Ponorogo

ujung tombak SAFE COMMUNITY yang

merupakan sarana publik.

Pengetahuan merupakan domain yang sangat penting untuk terbentuknya tindakan seseorang. Pengetahuan dipengaruhi oleh beberapa faktor diantaranya adalah usia, intelegensi, pemahaman, pengalaman, tingkat pendidikan, dan sarana informasi (Notoatmodjo, 2007). Maka pengetahuan tentang pertolongan pertama korban kecelakaan yang dilakukan oleh masyarakat perlu diteliti apakah menggunakan tehnik dan metode BLS yang benar atau tidak sehingga dapat meningkatkan angka keselamatan baik pada kecelakaan lalulintas maupun pada kasus atau kejadian sehari - hari. Penelitian ini mencoba menganalisis metode simulasi untuk meningkatkan pengetahuan masyarakat tentang BLS.

Tujuan penelitian ini untuk menganalisis efektifitas metode simulasi : role play terhadap peningkatan pengetahuan masyarakat tentang Basic Life Support (BLS)

Di Kelurahan Setono Kecamatan Jenangan Kabupaten Ponorogo.

\section{Bahan dan Metode}

Metode penelitian yang digunakan dalan penelitian ini adalah eksperimen dengan desain pre-ekspiremental designs jenis one group pretest - posttest design atau studi intervensi yaitu penelitian untuk menguji hipotesis sebab akibat dengan melakukan intervensi berupa pembelajaran dengan metode simulasi yang sebelumnya dilakukan observasi berupa pre test kemudian dilakukan observasi lagi berupa post test setelah dilakukan metode simulasi sehingga dapat dilihat perbedaan pengetahuan sebelum dan sesudah dilakukan simulasi. Penelitian dilakukan di Kelurahan Setono Kabupaten Ponorogo menggunakan tehnik pengambilan sampling kuota sampling dengan jumlah sample 80 responden. Instrumen yang yang digunakan berupa kuisioner pengetahuan BLS.

Pengambilan data penelitian dilakukan setelah mendapat ijin dari Kepala Desa Setono selanjutnya dibantu oleh perangkat desa responden dikumpulkan di satu tempat dan penelitian ini dilakukan 2 
Dinamika Kesehatan Jurnal Kebidanan dan Keperawatan Vol 10 No. 1 Juli 2019 ( ISSN: 2086-3454 EISSN: 2549-4058)

url: http://ojs.dinamikakesehatan.unism.ac.id DOI : https://doi.org/10.33859/dksm.v10i2

Efektifitas Metode Simulasi : Role Play Terhadap Peningkatan Pengetahuan Masyarakat Tentang Basic Life Support

(B1s) Di Kelurahan Setono Kabupaten Ponorogo

tahap. Setelah responden terkumpul peneliti

menjelaskan tujuan penelitian dan meminta

persetujuan responden, serta membagikan

kuisioner untuk diisi pada saat itu selanjutnya

peneliti memberikan simulasi : role play

setelah simulasi dibagikan kuisioner untuk

mengukur pengetahuan setelah simulasi.

Pengolahan data yang dilakukan

melalui tahap editing, koding dan scoring

serta tabulating dan data dianalisis melalui

prosedur univariat dan bivariat dengan

menggunakan uji statistic McNemar dengan

tingkat kemaknaan 95\% $(\alpha<0,05)$.

\section{Hasil}

Tabel 1. Distribusi Frekuensi Usia, Pendidikan, Pengalaman, Informasi, Pengetahuan Pre Test dan Pengetahuan Post Test Masyarakat tentang BLS Di Kelurahan Keamatan Jenangan Setono Ponorogo

\begin{tabular}{|c|c|c|c|}
\hline \multicolumn{2}{|c|}{ Variabel } & \multirow{2}{*}{$\begin{array}{c}\begin{array}{c}\text { Frekuen } \\
\text { si }\end{array} \\
5\end{array}$} & \multirow{2}{*}{$\begin{array}{c}\text { Persen (\%) } \\
6,2\end{array}$} \\
\hline Usia & $26-35$ & & \\
\hline \multirow[t]{4}{*}{ (Th) } & $36-45$ & 28 & 35,0 \\
\hline & $46-55$ & 22 & 27,5 \\
\hline & $56-65$ & 25 & 31,2 \\
\hline & Total & 80 & 100 \\
\hline \multirow{6}{*}{ Pendidikan } & SD & 15 & 18,8 \\
\hline & SMP & 20 & 25,0 \\
\hline & SMA & 36 & 45,0 \\
\hline & Perguruan & 9 & 11,2 \\
\hline & Tinggi & & \\
\hline & Total & 80 & 100 \\
\hline Pengalaman & Tidak & 77 & 96,2 \\
\hline \multirow[t]{3}{*}{ Menolong } & Pernah & 3 & 3,8 \\
\hline & Pernah & & \\
\hline & Total & 80 & 100 \\
\hline \multirow[t]{4}{*}{ Informasi } & Tidak & 77 & 96,2 \\
\hline & Pernah & 3 & 3,8 \\
\hline & Pernah & & \\
\hline & Total & 80 & 100 \\
\hline Pengetahuan & Buruk & 53 & 66,2 \\
\hline \multirow[t]{2}{*}{ Pretest } & Baik & 27 & 33,8 \\
\hline & Total & 80 & 100 \\
\hline Pengetahuan & Buruk & 8 & 10,0 \\
\hline \multirow[t]{2}{*}{ Posttest } & Baik & 72 & 90,0 \\
\hline & Total & 80 & 100 \\
\hline
\end{tabular}

Sumber : Data Primer 2017

Dari tabel 1. didapatkan dari total 80

masyarakat dalam penelitian ini sebagian

besar berusia $36-45$ tahun sebanyak 28

$(35,0 \%)$ responden. Sebagian besar

berpendidikan SMA sebanyak $36(73,3 \%)$

responden. Sebagian besar mempunyai

pengalaman menolong sebanyak $77(96,2 \%)$

responden. Responden yang belum pernah

mendapatkan informasi tentang BLS

sebanyak 77 (96,2\%) responden. Responden 
Dinamika Kesehatan Jurnal Kebidanan dan Keperawatan Vol 10 No. 1 Juli 2019 ( ISSN: 2086-3454 EISSN: 2549-4058)

url: http://ojs.dinamikakesehatan.unism.ac.id DOI : https://doi.org/10.33859/dksm.v10i2

Efektifitas Metode Simulasi : Role Play Terhadap Peningkatan Pengetahuan Masyarakat Tentang Basic Life Support

(Bls) Di Kelurahan Setono Kabupaten Ponorogo

yang mempunyai pengetahuan buruk tentang

BLS sebelum simulasi roleplay sebanyak 53

$(66,2 \%)$. Responden yang mempunyai

pengetahuan baik tentang BLS setelah

simulasi roleplay sebanyak $72(90 \%)$.

Tabel 2 Data Bivariat Pengetahuan Pretest dan Posttest simulasi : role play pada Responden di Kelurahan Kecamatan Jenangan Setono Ponorogo

Variabel /

Pengetahuan

Posttest

\begin{tabular}{ccccc} 
& $\begin{array}{c}\text { Buru } \\
\text { k }\end{array}$ & Baik & p \\
\hline $\mathbf{N}$ & $\%$ & $\mathbf{n}$ & $\%$ &
\end{tabular}

\begin{tabular}{lllllll} 
Pengetahu & Buruk & 8 & 10 & 45 & 56,2 & 0,00 \\
an Pretest & Baik & 0 & 0 & 27 & 27 & \\
\hline Total & & $\mathbf{8}$ & $\mathbf{1 0}$ & $\mathbf{7 2}$ & $\mathbf{9 0}$ &
\end{tabular}

Sumber : Data Primer 2017

Berdasarkan tabel 2. hasil penelitian didapatkan responden yang berpengetahuan sebelum simulasi roleplay buruk dan sesudah simulasi roleplay tetap buruk ada 8 orang. Responden yang berpengetahuan sebelum simulasi roleplay buruk dan sesudah simulasi roleplay berubah baik ada 45 orang. Responden yang berpengetahuan sebelum simulasi roleplay baik dan sesudah simulasi roleplay tetap baik ada 27 orang. Hasil uji statistik dengan uji Mc Nemar didapatkan Angka Significany menunjukkan angka 0,000. Karena nilai $\mathrm{p}<0,05$ maka dapat diambil kesimpulan bahwa pengetahuan antara sebelum dan sesudah simulasi role play berbeda secara bermakna.

\section{Pembahasan}

\section{Pengetahuan Masyarakat Tentang BLS} Sebelum Simulasi : role play.

Dari hasil penelitian pengetahuan tentang BLS sebelum simulasi role play didapatkan responden yang mempunyai pengetahuan buruk tentang BLS sebelum simulasi roleplay sebanyak $53 \quad(66,2 \%)$. Penelitian yang dilakukan Pergola (2009), didapatkan hanya sebagian kecil masyarakat mempunyai pengetahuan cukup tentang BHD. Penelitian Rajapakse, Noc, \& Kersnick (2010) didapatkan tingkat pengetahuan tentang ketrampilan RJP secara umum rendah. Sedangkan hasil penelitian yang dilakukan Erawati Susi (2015) menunjukkan seara umum pengetahuan masyarakat tentang BHD baik. Perbedaan hasil penelitian pada ketiga peneliti tersebut bisa terjadi karena beberapa faktor yaitu perbedaan kuisioner yang digunakan. Dimana terdapat perkembangan yang berkesinambungan tentang CPR, pembaruan tahun 2005, tahun 2010, tahun 2015 (American Heart Association, 2010). 
Dinamika Kesehatan Jurnal Kebidanan dan Keperawatan Vol 10 No. 1 Juli 2019 ( ISSN: 2086-3454 EISSN: 2549-4058)

url: http://ojs.dinamikakesehatan.unism.ac.id DOI : https://doi.org/10.33859/dksm.v10i2

Efektifitas Metode Simulasi : Role Play Terhadap Peningkatan Pengetahuan Masyarakat Tentang Basic Life Support

(Bls) Di Kelurahan Setono Kabupaten Ponorogo

Perkembangan ilmu CPR menunjukkan jika awalnya CPR hanya bisa dilakukan oleh tenaga medis, namun sekarang tehnik BLS disa dipelajari dan dilakukan oleh masyarakat awam maupun awam khusus yang sudah mendapatkan pelatihan. Ada beberapa faktor yang membatasi bystander untuk melakukan penyelamatan nyawa, yaitu ketakutan jika melakukan kesalahan saat CPR atau tehnik yang salah, ketakutan terkait kewajiban hukum dan transmisi penyakit jika memberikan ventilasi, karakteristik korban dan karakteristik sosiokultural daerah (Mani G, Danasekaran R, Annadurai K, 2014).

Hasil penelitian menunjukkan dari 77 responden yang tidak mendapatkan informasi didapatkan 51 responden mempunyai pengetahuan buruk sebelum role play. Studi yang dilakukan oleh Mani G, Danasekaran R, Annadurai K (2014) menunjukkan di Indonesia prevalensi bystander untuk melakukan CPR sangat rendah karena beberapa kendala dimana hal ini bisa mempengaruhi ketahanan hidup dari OHCA. Pemberian informasi yang baik dan diberikan dengan cara yang tepat melalui penyuluhan atau pelatihan secara berkesinambungan akan meningkatkan pengetahuan masyarakat tetntang BLS. Masyarakat tidak akan takut lagi untuk melakukan CPR karena takut salah, takut mencederai atau takut akan tertular penyakit akibat menolong sehingga mampu meningkatkan kualitas kesehatan.

\section{Pengetahuan Masyarakat Tentang BLS Setelah Simulasi : role play.}

Dari hasil penelitian pengetahuan tentang BLS setelah simulasi role play didapatkan responden yang mempunyai pengetahuan baik tentang BLS setelah simulasi roleplay sebanyak $72 \quad$ (90\%). Serangan jantung atau kasus henti nafas yang membutuhan identifikasi dan pemberian kompresi segera, sebagian besar terjadi di lingkungan luar Rumah Sakit, Masyarakat sebagai bagian yang paling sering pertama kali kasus tersebut (Abdullah Alanazi, 2013). BLS tidak hanya didapat dari pendidikan formal namun bisa didapat dari pendidikan non formal misalnya dengan pelatihan secara bekala baik pemula maupun untuk penyegaran. Dari 45 responden yang 
Dinamika Kesehatan Jurnal Kebidanan dan Keperawatan Vol 10 No. 1 Juli 2019 ( ISSN: 2086-3454 EISSN: 2549-4058)

url: http://ojs.dinamikakesehatan.unism.ac.id DOI : https://doi.org/10.33859/dksm.v10i2

Efektifitas Metode Simulasi : Role Play Terhadap Peningkatan Pengetahuan Masyarakat Tentang Basic Life Support

(Bls) Di Kelurahan Setono Kabupaten Ponorogo

berpendidikan SMA dan PT terdapat 41

responden yang berpengetahuan baik.

Penelitian ini sejalan dengan teori

Notoatmodjo (2003) dalam hutapea, Elda

Lunera (2012), dimana pendidikan

berbanding lurus dengan pengetahuan,

seseorang yang berpendidikan tinggi makan

berpengetahuan baik pula. Seseorang yang

mempunyai pendidikan tinggi akan lebih

mudah untuk menerima informasi, dimana

pada penelitian ini responden mendapat

informasi dengan tehnik simulasi role play

yaitu selain pemeberian teori peneliti

memperagakan BLS dengan media manekin.

Dengan peningkatan pengetahuan responden

tentang BLS ini sangat penting dengan

harapan bahwa setiap orang di masyarakat

tahu tentang Cardiopulmonary Resuscitation

(CPR) untuk indentifikasi dan

menyelamatkan nyawa.

Perbedaan Pengetahuan Masyarakat

tentang BLS Sebelum dan Sesudah

Simulasi : role play.

hasil penelitian didapatkan responden

yang berpengetahuan sebelum simulasi

roleplay buruk dan sesudah simulasi roleplay tetap buruk ada 8 orang. Responden yang berpengetahuan sebelum simulasi roleplay buruk dan sesudah simulasi roleplay berubah baik ada 45 orang. Responden yang berpengetahuan sebelum simulasi roleplay baik dan sesudah simulasi roleplay tetap baik ada 27 orang. Hasil uji statistik dengan uji Mc Nemar didapatkan Angka Significany menunjukkan angka 0,000. Karena nilai $\mathrm{p}<$ 0,05 maka dapat diambil kesimpulan bahwa pengetahuan antara sebelum dan sesudah simulasi role play berbeda secara bermakna.

Resusitasi kardiopulmoner bystander (CPR) penting untuk bertahan hidup dari luar rumah sakit serangan jantung (OHCA). Namun, penelitian terbaru menunjukkan bahwa kualitas CPR adalah penting dan sering diabaikan faktor yang mempengaruhi kelangsungan hidup. Faktor individu, pelatihan, kesadaran, teknik dan kelelahan penyelamat dapat mempengaruhi kualitas CPR. Komponen kualitas CPR meliputi tingkat, rasio, kedalaman dan rasio kompresi ventilasi Ong Eng Hock Marcus (2011). 
Dinamika Kesehatan Jurnal Kebidanan dan Keperawatan Vol 10 No. 1 Juli 2019 ( ISSN: 2086-3454 EISSN: 2549-4058)

url: http://ojs.dinamikakesehatan.unism.ac.id DOI : https://doi.org/10.33859/dksm.v10i2

Efektifitas Metode Simulasi : Role Play Terhadap Peningkatan Pengetahuan Masyarakat Tentang Basic Life Support

(Bls) Di Kelurahan Setono Kabupaten Ponorogo

Beberapa strategi telah disarankan

agar meningkatkan kualitas CPR di

masyarakat kita. Ini meliputi penelitian, pelatihan, pendidikan dan penggabungan teknologi tepat guna yang mengukur dan memberi umpan balik kualitas CPR. Salah satunya dengan metode simulasi (role playing) merupakan proses pembelajarannya yang mengutamakan pola permainan dalam bentuk dramatisasi. Dramatisasi dilakukan oleh kelompok dengan mekanisme pelaksanaan yang diarahkan oleh pelatih untuk melaksanakan kegiatan yang telah ditentukan / direncanakan sebelumnya (Sri Anitah, W (2012). Pada penelitian ini responden adalah masyarakat awam untuk tehnik CPR adalah compresi only, renponden ditunjukkan drama terkait asus henti nafas atau henti jantung serta bagai mana cara memberikan pertolongan dengan BLS yang tepat kemudian responden diberi kesempatan melakukan tehnik kompresi yang benar dan tepat. Setelah simulasi responden diberikan test lagi sehingga dapat diketahui perbedaan yang bermakna pengetahuan msyarakat tentang BLS sebelum dan setelah simulasi. Pemberian siimulasi BLS ini sangat penting dengan harapan bahwa setiap orang di masyarakat tahu tentang Cardiopulmonary Resuscitation (CPR) untuk menyelamatkan nyawa dan meningkatkan kualitas kesehatan masyarakat.

\section{Simpulan}

Perkembangan ilmu CPR menunjukkan jika awalnya CPR hanya bisa dilakukan oleh tenaga medis, namun sekarang tehnik BLS disa dipelajari dan dilakukan oleh masyarakat awam maupun awam khusus yang sudah mendapatkan pelatihan. Ada beberapa faktor yang membatasi bystander untuk melakukan penyelamatan nyawa, yaitu ketakutan jika melakukan kesalahan saat CPR atau tehnik yang salah, ketakutan terkait kewajiban hukum dan transmisi penyakit jika memberikan ventilasi, karakteristik korban dan karakteristik sosiokultural daerah.

Beberapa strategi telah disarankan agar meningkatkan kualitas CPR di masyarakat kita. Ini meliputi penelitian, pelatihan, pendidikan dan penggabungan teknologi tepat guna yang mengukur dan memberi umpan 
Dinamika Kesehatan Jurnal Kebidanan dan Keperawatan Vol 10 No. 1 Juli 2019 ( ISSN: 2086-3454 EISSN: 2549-4058)

url: http://ojs.dinamikakesehatan.unism.ac.id DOI : https://doi.org/10.33859/dksm.v10i2

Efektifitas Metode Simulasi : Role Play Terhadap Peningkatan Pengetahuan Masyarakat Tentang Basic Life Support

(B1s) Di Kelurahan Setono Kabupaten Ponorogo

balik kualitas CPR. Pada penelitian ini responden adalah masyarakat awam untuk tehnik CPR adalah compresi only, renponden ditunjukkan drama terkait asus henti nafas atau henti jantung serta bagai mana cara memberikan pertolongan dengan BLS yang tepat kemudian responden diberi kesempatan melakukan tehnik kompresi yang benar dan tepat. Setelah simulasi responden diberikan test lagi sehingga dapat diketahui perbedaan yang bermakna pengetahuan msyarakat tentang BLS sebelum dan setelah simulasi. Pemberian siimulasi BLS ini sangat penting dengan harapan bahwa setiap orang di masyarakat tahu tentang Cardiopulmonary Resuscitation (CPR) untuk menyelamatkan nyawa dan meningkatkan kualitas kesehatan masyarakat

\section{Ucapan Terimakasih}

\section{Rektor Universitas Muhammadiyah}

Ponorogo dan Dekan Fakultas Ilmu

Kesehatan Universitas Muhammadiyah

Ponorogo atas support serta fasititasnya.

\section{Daftar Pustaka}

Abdullah Alanazi, Bin-Hotan, M. ALqahtani, H. ALhalyabah, A. Alanazi and Aloraibi, Saleh (2013), Community Awareness About Cardiopulmonary Resuscitation Among Secondary School Students in Riyadh. World Journal of Medical Sciences 8 (3): 186-189, 2013.

Anitah, Siti.2012. Media Pembelajaran. Surakarta: Yuma Pustaka.

AHA Journal, (2005, November 28). 2005 American Heart Association guidelines for cardiopulmonari resucitation and emergency cardiovascular care. Februari 232015. http.circ.ahajournals.org/content/112/2 4 _suppl/IV1.full

Dahlan, M Sopiyudin, (2008). Statistik Kedokteran dan Kesehatan, Jakarta : Salemba Medika

Dephub RI (2014). Kecelakaan Jalan Raya Yang Melibatkan Sepeda Motor. (Maret, 2015). http://www.dephub.go.id/read/berita/31 2709/kecelakaan-lalu-lintas.

Erawati Susi. (2015), Tingkat pengetahuan masyarakat tentang Bantuan Hidup Dasar di Kota Administrasi Jakarta Selatan

Frame Scott B. (2003). PHTLS: Basic and Advance Prehospitalntrauma life support.(5ed).Missouri; Mosby

Hurlock, E.B. (1998). Psikologi Perkembangan. Suatu Pendekatan Sepanjang Rentang Kehidupan. Edisi 5 : Jakarta : Erlangga.

Mani G., Danasekaran R, Annadurai K. (2014), Bystander cardiopulmonary resuscitation: Equipping communities to save lives. Prog Health Sci 2014, Vol 4, No2 Bystander CPR for community 
Dinamika Kesehatan Jurnal Kebidanan dan Keperawatan Vol 10 No. 1 Juli 2019 ( ISSN: 2086-3454 EISSN: 2549-4058)

url: http://ojs.dinamikakesehatan.unism.ac.id DOI : https://doi.org/10.33859/dksm.v10i2

Efektifitas Metode Simulasi : Role Play Terhadap Peningkatan Pengetahuan Masyarakat Tentang Basic Life Support (Bls) Di Kelurahan Setono Kabupaten Ponorogo

Moewardi, (2003). Materi Pelatihan PPGD. Surakarta.

N. Kartikawati Dewi. (2011). Dasar - Dasar Keperawatan Gawat Darurat. Jakarta: Salemba Medika

Notoatmodjo. (2007). Promosi Kesehatan dan Ilmu Perilaku. Jakarta: Rineka Cipta

Ong E H M. (2011), Improving the quality of $C P R$ in the community. Singapore Med J 2011; 52(8) : 586

Pergola. (2009), Lay People Basic Life Support Trainning in Primary Schools Education, Medical Education 376-80 Rajapakse , Noc, \& Kersnik. (2010), Public Knowledge of Cardiopulmonary
Resuscitation in Public of Slovenia. Wiener Klin Wochenschr, 667-672

Resucitation council. (2010, Oktober). Adult Basic Life Support. Februari 232015. http://www.resus.org.uk/page/.bls.pdf

Resucitation council. (2015). AHA Guidelines Update For PR and ECC. Maret 2016. http://www.cercp.org $>$ recursos $>$ Guias2 015

Sunyoto.(2010. Agustus 3). Presentasi, case study, simulasi, Maret 2015. http://www.fkm.unsri.ac.id/index.php? option=com_content\&view $=$ article $\&$ id $=44$ :presentasi-case-studysimulasi\&catid $=8$ :informasi 